\title{
LA DOCTRINA DEL SHOCK Y LA ACCIÓN DE GOBIERNO EN MÉXICO: LA CAPACIDAD DE RESPUESTA ANTE LA COVID-19 Y LAS DINÁMICAS SUBNACIONALES
}

\author{
Aldo Adrián Martínez-Hernández ${ }^{1}$ \\ aldomaher@usal.es \\ Centro de Investigación y Docencia Económicas (CIDE), México \\ José de Jesús Pérez Martínez ${ }^{2}$ \\ josedejesus.perez@educiac.org.mx \\ Educación y Ciudadanía,A.C, México
}

La pandemia ocasionada por el virus SARS-CoV-2 causante de la enfermedad COVID-19 ha sido una catástrofe sanitaria a nivel mundial, lo cual la convierte en un fenómeno que impone un escenario de crisis sostenida y como un momento en el que las políticas públicas han sido reformadas constantemente, especialmente en materia económica y de salud en todos los niveles de gobierno. Este escenario de cambio constante en las políticas públicas a nivel estatal permite revisar cuáles han sido los efectos de dichos cambios en diferentes entidades de la República Mexicana. Para ello, el presente artículo se pregunta ¿cómo y cuáles entidades han sido más y menos afectadas por la pandemia? y ¿cómo y cuáles entidades han manifestado mayor capacidad de respuesta ante la crisis? Dicho cuestionamiento es respondido a partir del análisis de las diferencias y similitudes entre entidades federativas respecto a sus acciones frente a la crisis sanitaria, destacando las principales políticas públicas que fueron implementadas como respuesta emergente a este escenario crítico.

Palabras clave: COVID-19; shock; políticas públicas; pandemia, México, federalismo

\footnotetext{
Postdoctoral Research Fellow en el Centro de Investigación y Docencia Económicas (CIDE) Región Centro. Doctor y Maestro en Ciencia Política por la Universidad de Salamanca, España. Maestro en Asuntos Políticos y Políticas Públicas por El Colegio de San Luis A.C, México y Lic. en Ciencias Políticas y Administración Pública por la Universidad Autónoma de Aguascalientes, México. Miembro del Sistema Nacional de Investigadores del CONACYT.

2 Doctor en Ciencias Sociales y Maestro en Asuntos Políticos y Políticas Públicas por El Colegio de San Luis A.C., México. Estancia de Investigación sobre Criminalidad y Accountability en el Instituto de Sociología de la Academia Checa de Ciencias en Praga. Lic. Derecho por la Universidad Autónoma de San Luis Potosí. Coordinador de Investigación e Incidencia en Educación y Ciudadanía, A.C., México.
} 


\section{SHOCK DOCTRINE AND THE GOVERNMENT ACTION IN MEXICO:THE CAPACITY OF RESPONSE TO THE COVID-19 AND THE SUBNATIONAL DYNAMICS.}

The pandemic caused by the SARS-CoV-2 virus that causes the COVID-19 disease has been a global health catastrophe, which makes it a natural phenomenon that imposes a sustained crisis scenario and as a moment in which the public policies have been constantly reformed, especially in economic and health matters at all levels of government and affecting all areas of life in society. This scenario of constant change in public policies at the state level allows us to review what the social effects of these changes have been in different entities of the Mexican Republic. To do this, this article will analyze the differences and similarities between states regarding their actions in the face of the health crisis, highlighting the main public policies that were implemented as an emergent response to this critical scenario. Determining with this, which entities have been (more or less) affected, and which have shown greater response capacity.

Key words: COVID-19; shock; public policy; pandemic, Mexico, federalism 


\section{Introducción}

Las políticas públicas como procesos de toma de decisiones dependen, en gran medida, del factor vinculado a los intereses, ya sea de los gestores, implementadores, partidos o de los actores en general que tienen cierta injerencia y racionalidad dentro del proceso de toma de decisiones, esta última ciertamente limitada como afirmaba Simon $(1957 ; 1989)$. Idealmente las políticas públicas deberían contener mecanismos para la inclusión participativa de la sociedad en sus diferentes etapas. Su inclusión dota de una mayor legitimidad y al mismo tiempo, reduce la limitación que presenta su racionalidad, pues al estructurarse sobre el soporte social también ostentarán mayor conocimiento, información y mayor número de alternativas para enfrentar los problemas públicos. Sin embargo, en la mayoría de los casos, los intereses se ven motivados por algo más allá de lo visible en primera instancia, más bien comparten lazos profundos y subyacentes que no son tan evidentes, tal como ocurre con las fuerzas del mercado, que dependiendo la corriente pueden o no revelar una influencia en la elaboración de las políticas públicas, aunque es claro que no es el único tipo de motivación que interactúa. Este tipo de fuerzas profundas del mercado se han identificado con lo que Naomi Klein (2007) denomina “capitalismo del desastre" que funciona a través de la doctrina del shock.

En esta doctrina, las políticas formadas en épocas de desastre consideran los momentos de crisis de todo tipo, desde guerras o amenazas humanas, hasta catástrofes naturales, pues son los momentos adecuados para poder ofrecer alternativas a las sociedades que en otras circunstancias no aceptadas tan fácilmente, es decir, desde la visión del Gobierno este tipo de crisis son una oportunidad para hacer reformas, modificación de políticas públicas o generar nuevas políticas con poca resistencia y en lapsos de tiempo más cortos. Lo anterior es relevante en el contexto actual en que la pandemia ocasionada por el virus SARS-CoV-2 causante de la enfermedad COVID-19 ha sido una catástrofe sanitaria a nivel mundial, y que según los pronósticos durará por más de un par de años, lo cual la convierte en un fenómeno natural que impone un escenario de crisis sostenida y como un momento en el que las políticas públicas han sido reformadas constantemente, especialmente en materia económica y de salud en todos los niveles de gobierno. Particularmente, este escenario de cambio constante en las políticas públicas a nivel estatal permite revisar cuáles han sido los efectos sociales de dichos cambios en diferentes entidades de la República Mexicana. Aunque dichos efectos se pueden propagar en distintos ámbitos, como la educación, el trabajo, la cultura, la vida familiar, la justicia o el ambiente, aquí se analizarán las principales diferencias entre entidades en cuanto al número de infectados y de personas que han fallecido a consecuencia de políticas públicas diferenciadas o con grandes áreas de mejora, que son en su mayoría políticas implementadas como respuesta emergente a este escenario de crisis.

Para ello, el artículo se estructura en cuatro secciones. La primera esboza los planteamientos teóricos de referencia, en el que se atribuye importancia a la doctrina 
de shock como marco estructural de la acción de gobierno en periodos de crisis, para ello, se puntualizan las ideas esenciales de la teoría y se diseña su aplicación en el contexto particular de análisis. La segunda sección desarrolla la metodología utilizada, partiendo de las dimensiones analíticas de la acción de gobierno a nivel estatal y las especificidades de esta investigación. La tercera sección contrasta la teoría en la realidad subestatal mexicana, partiendo de un análisis descriptivo y exploratorio en las entidades del país. Finalmente, la última sección destaca los resultados obtenidos y cierra con el apartado de conclusiones.

\section{El shock como marco analítico}

En la doctrina del shock, Naomi Klein (2007: 595) define a un estado de shock como "un momento en el que se produce una pausa entre acontecimientos que se están sucediendo a gran velocidad y la información existente acerca de ellos", es decir, se abre una ventana de oportunidad para hacer esos cambios en la política desde el momento en que se percibe la gravedad de la crisis o el momento traumático, hasta que se implementan los cambios y se supera dicha situación, que es cuando se reconoce otra etapa y que el momento de crisis ha pasado. Es hasta entonces que se va recuperando la comprensión y orientación del panorama social previo o se inicia el proceso de socialización hacia el nuevo panorama que contenga los cambios a los que hay que acostumbrarse: "nueva normalidad". Para el shock se establecen tres elementos fundamentales: la confusión, la desorientación y la sorpresa que otorgan la ventaja a quienes están preparados para proponer un cambio de todo tipo como una salida a esa situación complicada.

Es cierto que cuando Klein (2007) propone esto, lo hace como análisis o propuesta del capitalismo del desastre pensando en niveles de política pública de Estado y lo hace específicamente en términos de política económica a un nivel mundial interconectado en un panorama en el que la política neoliberal dominante depende de un grupo de economistas de la escuela de Chicago, liderada hasta su muerte por Milton Friedman. La propuesta en este artículo es revisar cómo es posible aplicar este mismo postulado de la doctrina del shock como un momento de aprovechamiento de crisis o ventana de oportunidad para hacer reformas a las políticas públicas a nivel subestatal y local, además del nacional, para así verificar que no solo ocurre con las políticas de corte económico, sino que también puede ocurrir en varios rubros, en este caso de las áreas sociales y de salud.

En el contexto mexicano, cuando al presidente de México Andrés Manuel López Obrador le informaron públicamente la noticia del arribo de la pandemia al país a finales de febrero de 2020, él respondió con un refrán mexicano diciendo que "esto nos había caído como anillo al dedo"3 una respuesta que fue duramente criticada,

3 Animal Político (2020). “COVID-19 y crisis vinieron 'como anillo al dedo': AMLO” en animalpolítico.com. Recuperado el 8 de mayo de 2021: https://www.animalpolitico.com/2020/04/ crisis-economica-salud-transitoria-saldremos-ponto-amlo/ 
y que probablemente refería a las políticas sociales y de austeridad implementadas hasta ese momento por el gobierno. Al observar desde otra óptica, puede que tenga una justificación al menos para su punto de vista como gobernante, pues siguiendo lo propuesto por la doctrina del shock, una crisis de estas dimensiones es una gran oportunidad en cuanto a posibilidades de cambio político.

Una de las premisas básicas que describe Klein (2007) es que luego de las experiencias traumáticas, según narra sobre las vivencias de Ewen Cameron, se va formando esta doctrina y que pueden extrapolarse a las sociedades cuando se analizan los casos del capitalismo del desastre, en el que se busca la imposición o el reforzamiento del modelo de desarrollo neoliberal. En términos generales, en esta pandemia un punto a destacar es que ambas cosas se presentaron en un nivel global: esta experiencia traumática se fue manifestando inicialmente en países que son potencias económicas mundiales y de ahí llegó al resto del mundo, con pocos países capaces de aislarse. Al tiempo que el modelo de desarrollo neoliberal se impulsó por características y hegemonías globales, al menos en cuanto a sus herramientas, metodologías, tecnología, procesos de comunicación, educación y protección de la salud, también es notoria la desigualdad que se da entre países, pues no todos tienen las capacidades estructurales para ir al mismo ritmo en el uso, presencia y adaptación de la tecnología o en vacunación (Blau, 2020; Sánchez, 2020).

Como parte de las amenazas o temores necesarios para vivir en el shock, un factor fundamental para esta doctrina es el miedo, que será utilizado como un efecto dominador para que la población vulnerable o temerosa acepte todo tipo de políticas y cambios de una manera rápida, en busca de una solución a ese miedo, esta ventana puede ser utilizada como menciona Klein (2007) para incorporar reformas económicas, pero no solo ello sino también aplica para todo tipo de reformas que pueden ir incluso en contra de los derechos de las personas, como fue el caso de la suspensión de garantías que se presentó de manera momentánea en varios países.

Las políticas que se generan en estas situaciones o que se aceptan, son parte de una solución que presenta a la sociedad en estado de vulnerabilidad. Una frontera con ese escenario indeseable al que no desea llegar, en este caso de análisis, es la velocidad con la que se propagó el virus y su tasa de letalidad que generó un escenario en donde muchas personas fallecieron, por lo que todo tipo de políticas que representaron alguna alternativa considerable fueron validadas, ya sea mediante cambios legislativos tradicionales o por su urgencia mediante decretos por parte del Ejecutivo en distintos países y entidades federativas.

Según Klein (2007: 31) “el modus operandi clásico (...), esta forma fundamentalista del capitalismo siempre ha necesitado de catástrofes para avanzar. Sin duda las crisis y las situaciones de desastre eran cada vez mayores y más traumáticas" ya que es un postulado que está presente en una situación que ha sido un choque en varios aspectos para muchos sectores de la población, pues la pandemia por COVID-19 ha perturbado los ámbitos laborales, familiares, educativos y emocionales de gran 
parte de la población; también es cierto que hay ciertos sectores de la economía que a pesar de la crisis no se han detenido, e incluso han tenido un impulso mayor, como el comercio en línea, las clases virtuales, las herramientas tecnológicas, así como el equipo de protección sanitaria e higiene personal, que a fin de cuentas son producidos por todo tipo de corporaciones a nivel mundial.

Otro rasgo en común del capitalismo del desastre con este tipo de políticas es que a un largo plazo, después de implementarse, las desigualdades en vez de reducirse son aumentadas; eso ya puede observarse con las brechas de desigualdad y los cambios que hubo durante este año transcurrido, pues los empleos más seguros fueron los de las clases altas y eran esas mismas clases las capaces de adaptarse al uso de herramientas tecnológicas, al igual que los comercios que más posibilidades tuvieron de sobrevivir fueron los comercios grandes, mientras que los trabajadores menos afectados eran quienes ya se encontraban en la formalidad o con algún tipo de protección de Seguridad Social (Galletta y Giommoni, 2020; Zazueta y Jaramillo, 2020).

Cabe resaltar que al no ser reformas que se desarrollan plenamente en el ámbito económico, ni a nivel de las Políticas de Estado, no aplican totalmente los principios básicos del corporativismo mencionados por Klein (2007), es decir, la libertad de movimiento absoluta para el sector privado y el mercado, la eliminación del rol público del Estado y el gasto social reducido o nulo. En ocasiones fue al contrario: corrió a cargo del Estado, pero en conjunto con otros actores como el Ejército, las paraestatales, la sociedad civil organizada y el mismo sector privado para llevar a cabo las acciones; hubo restricciones a ciertos sectores del comercio o del mercado que no fueran de extrema necesidad; y el gasto social aumentó para poder contener los efectos de la pandemia y dar atención médica a la población que lo necesitara o servicios funerarios en su caso. En México, este gasto tuvo que ser obtenido del mismo presupuesto para el año fiscal que ya estaba en curso (2020) y para 2021 tuvo que incorporarse en el nuevo presupuesto, pero con pocas posibilidades de ajustes en los impuestos y con el resto de los rubros económicos también con acciones por cumplir, el mismo monto de ingresos estatales tenían ahora más funciones por cubrir (Cejudo, et., al., 2020).

Uno de los métodos usados para reforzar la doctrina del shock que destacan es la tortura, tanto a nivel individual como colectivo para obligar a quien la sufre a hacer concesiones contra su voluntad, entre los métodos que recupera Klein (2007) se encuentra precisamente el aislamiento, al que la mayoría de la población tuvo que someterse en el caso de la actual pandemia. A esto agregamos otros tipos de tortura psicológica como las enfermedades o trastornos que se han presentado en altos números de personas que regresaron a hacer sus labores en casa, al compartir lugares hacinados o que no están adaptados para trabajar con varias personas en simultáneo, además de los traumas que se pueden agregar por pérdida de empleo, por violencia, por crímenes o por pérdidas a causa de salud que se agregan, y la alteración social que crece con el alcance que tienen las redes sociales y los contenidos o noticias (verdaderas o falsas) en ellas (Korstanje, 2012; Devine, Gaskell, Jennings y Stoker, 2020). 
Específicamente sobre los métodos de tortura, la doctrina del shock propone que deben de ser improvisados o imprevistos para tomar por sorpresa a quien recibe el shock, tal como ocurrió con el COVID-19; además se plantea que reconocer una experiencia traumática provocará pérdida de la memoria en mayor o menor medida, y que con la repetición de los shocks la memoria del paciente irá siendo borrada por lo menos en relación al evento traumático y serán como una pizarra en blanco para proponer cualquier alternativa, lo que representa un panorama mejor para esa experiencia, por lo que, probablemente muchas de las maneras en las que se solían implementar las políticas de educación, de trabajo, de salud y de comercio, tendrán una nueva forma para llevarse a cabo a partir de ahora, la sociedad luego de una sesión de shocks que se ha prolongado por más de un año, está en una buena disposición para cambiar sus maneras tradicionales de comportamiento (Lange, 2010).

El estado vulnerable en la psique social permite el proceso de creación en el que la sociedad espera volver a nacer de nuevo, algo que en México fue reconocido a nivel federal como la "nueva normalidad", un panorama o expectativa al que se pensaba llegar pronto, pero no se terminó de alcanzar por completo, a muchas personas simplemente les será imposible recuperar lo que consideraban normal además de su rutina: su empleo u oficio, su forma de vida, su patrimonio, su salud o la vida de sus familiares y la dinámica que de ello dependía. Cabe mencionar que otro de los mecanismos reconocidos por Klein (2007) como posibles detonantes del shock es la deuda, y como se ha mencionado anteriormente, este panorama ha hecho que ciertos países que no tengan el mismo acceso a las vacunas o a la protección de salud, algo que marca diferencias entre ellos, por lo que el endeudamiento ha sido diferente para cada país, al igual que el presupuesto para poder dedicar a la investigación y al avance tecnológico, o a la protección de salud, así que la deuda que se genere a futuro dejará a los países menos desarrollados en las condiciones propicias para que se presenten más situaciones de crisis comúnmente, que probablemente sí puedan ser aprovechadas desde un punto de vista meramente económico.

De igual forma. la sola presencia de la deuda obliga a que los países más necesitados se vean en una posición más comprometida ante instituciones financieras internacionales como el Banco Mundial o el Fondo Monetario Internacional, que harán más proclive la situación en la que podrán intervenir condicionando la política interna de dichos Estados a cambio de apoyos económicos para salir adelante de las deudas, en una época en la que los intereses pueden duplicar o triplicar las deudas de los países en pocos años. Esta desigualdad no ocurre solo entre los Estados, también entre las personas. El nivel de endeudamiento o de riesgo ha sido mayor para los sectores menos favorecidos, o para aquellos que permanecen en la informalidad, o que acumulan diversas condiciones de vulnerabilidad, pues al no poder desempeñar por completo su labor con una protección social o cumplir con los mínimos para una vida digna y decente, deben destinar parte de su presupuesto familiar cuando llega a presentarse una situación de salud por atender o algún otro gasto relacionado. Este gasto de presupuesto inesperado puede llevarle fácilmente al endeudamiento 
que les restringirá derechos tarde o temprano en otros ámbitos (Cejudo, et., al., 2020; Galletta y Giommoni, 2020; Zazueta y Jaramillo, 2020; Benton, Rissler y Wagner, 2020).

\section{Método}

Como se refirió al inicio del texto, el artículo analiza las diferencias y similitudes entre entidades federativas mexicanas respecto a sus acciones frente a la crisis sanitaria, destacando las principales políticas públicas que fueron implementadas como respuesta emergente a este escenario crítico. Lo anterior intentará dar respuesta a dos cuestionamientos principales: ¿cómo y cuáles entidades han sido más y menos afectadas por la pandemia? y ¿cómo y cuáles entidades han manifestado mayor capacidad de respuesta ante la crisis? De acuerdo con las interrogantes anteriores, la investigación, desde una perspectiva descriptiva, desarrolla las dimensiones observadas por Klein (2007) a la luz de los objetivos de las acciones de gobierno frente a la crisis sanitaria.

Como supuesto teórico, se asume que los gobiernos nacional y subestatales desarrollaron acciones encaminadas a la contención de la enfermedad que permitiera mantener la economía a la par de la limitación de fallecimientos a causa de la COVID 19. En este sentido, y de acuerdo con lo postulado por Klein (2007) se esperaría observar que las entidades con mayor desarrollo económico sufrieran mayores estragos sanitarios pese a su capacidad de respuesta y estructura sanitaria. Lo anterior esboza que las acciones de gobierno para enfrentar la pandemia de las diversas entidades mexicanas tuvieron efectos diferenciados debido a su estructura económica, social y sanitarias previas, consolidando con ello una afectación mayor a entidades vulnerables con niveles altos de pobreza (Capano, et. al., 2020; Woo, 2020; Capano, 2020; Galletta y Giommoni, 2020; Zazueta y Jaramillo, 2020).

Para contrastar los supuestos anteriores, la investigación se estructura con base en el análisis de cuatro dimensiones. La primera, 1) acciones de política pública, observa las políticas sociales y económicas desarrolladas por las entidades federativas para contrarrestar los efectos de la pandemia. Para ello se identifican las acciones concretas observadas por Cejudo, et., al., $(2020)^{4}$, las cuales clasifica en cuatro elementos: a) programas y políticas de asistencia social; b) programas de digitalización administrativa; c) programas de estímulo económicos; d) programas fiscales (Shringare y Fernandes, 2020; Kincaid y Leckrone, 2020; Rocco, Béland y Waddan, 2020; McDonald III, Goodman, y Hatch, 2020; Fowler; Kettler y Witt, 2021). La segunda dimensión observa 2) la estructura sanitaria, la cual considera la

4 Laboratorio Nacional de Políticas Públicas: México. Disponible en: https://nppmicrositio. shinyapps.io/FederalismoEnCovid/ / Federalismo en COVID: Plataforma interactiva sobre políticas estatales ante la pandemia por COVID-19: https://www.cide.edu/coronavirus/federalismo-covid/ / https://lnppmicrositio.shinyapps.io/PoliticasEconomicasCovid19/ 
situación previa a la pandemia y se observa a partir de cuatro elementos ${ }^{5}$ a) Población sin carencia por acceso a los servicios de salud; b) Tasa de consultorios; c) Tasa de médicos; d) Población que tardaría menos de dos horas en llegar a un hospital; e) Población derechohabiente que recibió servicios preventivos; f) Tasa de camas censables $^{6}$ (Macal, 2020; Lazreg, Angel y Saint-Martin, 2020). La tercera dimensión, 3) actividad económica, contempla dos elementos (Benton, Rissler y Wagner, 2020). Por un lado, observa el desempeño económico que es observado previo a la pandemia y hasta el momento actual a partir del Indicador Trimestral de la Actividad Económica Estatal del Instituto Nacional de Estadística y Geografía (INEGI) ${ }^{7}$. El segundo elemento es la observación de la pobreza y pobreza extrema, identificando las condiciones sociales previas a la pandemia en cada entidad federativa (Galletta y Giommoni, 2020; Zazueta y Jaramillo, 2020), dicha información se obtiene a partir de la medición realizada por del Consejo Nacional de Evaluación de la Política de Desarrollo Social (CONEVAL) ${ }^{8}$. Finalmente, la última dimensión identifica la evolución estatal de la pandemia a partir de cuatro variables: 1) población ${ }^{9}$,2) casos confirmados COVID 19,3) defunciones, tasa de incidencia y 4) tasa de letalidad. ${ }^{10}$

Con base en lo anterior, la investigación analiza las 32 unidades subnacionales de México desde una perspectiva comparativa y sistémica lo cual permite definir las diferencias y similitudes entre estos. Para ello, se utiliza una perspectiva empírica y descriptiva que incluye técnicas estadísticas (correlaciones bivariadas) y análisis

Secretaría de Salud del Gobierno de México: Plataforma: https://coronavirus.gob.mx/ / https:// datos.covid-19.conacyt.mx/\#DOView / http://www.dgis.salud.gob.mx/contenidos/basesdedatos/ da_recursos_gobmx.html

Dirección General de Epidemiología: Sistema de Información de la Red IRAG. Secretaría de Salud https://www.gits.igg.unam.mx/red-irag-dashboard/reviewHome

Sistema de Información de Derechos Sociales del Consejo Nacional de Evaluación de la Política de Desarrollo Social (CONEVAL). Estimaciones del CONEVAL sobre la base del MCS-ENIGH 2008, 2010, 2012, 2014 y el MEC del MCS-ENIGH 2016 y 2018: https://www.coneval.org.mx/ Medicion/Paginas/Sistema-de-informacion-de-derechos-sociales.aspx / Módulo de Condiciones Socioeconómicas MCS-ENIGH 2010 y el Modelo Estadístico 2018 para la continuidad del MCSENIGH. Módulo Sectorial (SINAIS) 2012-2017, Recursos en Salud, Cubos dinámicos de la SSADGIS, 2012 y 2017

6 Las diversas tasas son ponderadas por la población de cada entidad federativa.

7 Indicador Trimestral de la Actividad Económica Estatal del Instituto Nacional de Estadística y Geografia (INEGI) https://www.inegi.org.mx/app/saladeprensa/noticia.html?id=6475

8 Consejo Nacional de Evaluación de la Política de Desarrollo Social (CONEVAL) https://www. coneval.org.mx/Medicion/MP/Paginas/Pobreza-2018.aspx

9 Censo de Población y Vivienda 2020 (Censo 2020) del Instituto Nacional de Estadística y Geografía (INEGI) https://www.inegi.org.mx/programas/ccpv/2020/

10 Secretaría de Salud del Gobierno de México: Plataforma https://coronavirus.gob.mx/ / https:// datos.covid-19.conacyt.mx/\#DOView / http://www.dgis.salud.gob.mx/contenidos/basesdedatos/ da_recursos_gobmx.html

Dirección General de Epidemiología: Sistema de Información de la Red IRAG. Secretaría de Salud https://www.gits.igg.unam.mx/red-irag-dashboard/reviewHome 
espacial (mapas y clústers jerárquicos). Con ello se obtendrá una visión holística y espacial de los efectos de la pandemia y las acciones generadas por los gobiernos nacional y subestatales para combatirla.

\section{Análisis y datos}

\subsection{La pandemia y la acción de gobierno}

Desde el inicio de la pandemia en México a finales de febrero de 2020, las distintas fases de la misma definieron escenarios que facilitaron la separación de la salud con los demás temas de la agenda política nacional, precisamente porque se designó a un vocero encargado de la información y comunicación respecto a la emergencia sanitaria. El Subsecretario de Prevención y Promoción de la Salud, el Dr. Hugo López-Gatell Ramírez de la Secretaría de Salud, ha sido el encargado central de la estrategia y de la comunicación que diariamente, desde el primer caso de contagio, ha informado a la sociedad. Lo cual ha permitido que el presidente se pueda enfocar en otros temas de interés político, además de la pandemia. Algo similar ha ocurrido con economía y educación, asignando conferencias diarias previas a las de salud, por lo menos durante el primer año de la crisis sanitaria (Cejudo, et., al., 2020; Zazueta, y Jaramillo 2020; Macal, 2020).

Cabe destacar que los procesos de comunicación institucional, desde la llegada de López Obrador al Poder Ejecutivo en 2018, han evidenciado dinámicas que constituyen un nuevo paradigma en el país. Por un lado, la estrategia comunicativa del gobierno ha centralizado la comunicación mediante la inclusión de conferencias matutinas del presidente, en donde se invita a secretarios de Estado y otros actores como empresarios y miembros de la sociedad civil a anunciar acciones y programas y a responder dudas de la prensa. Desde el inicio de la gestión de López Obrador se ha llevado a cabo una conferencia por día de gobierno, aun en fines de semana el presidente comunica en redes sociales un mensaje a la sociedad. Esta condición personaliza y centraliza la emisión de mensajes del gobierno. Con ello, el presidente tiene la capacidad de controlar la agenda mediática bajo los intereses del gobierno, debido en parte a su liderazgo carismático, capacidad de emisión de mensajes y vías de comunicación alternativas como las redes sociales (Cejudo, et, al., 2020; Taggart y Pirro, 2021).

Estos dos procesos han evidenciado una combinación de modelos de comunicación, aunque con una mayor tendencia a la personalización de una visión política por parte del presidente y una noción que en principio fue técnica por parte del subsecretario de salud. En este sentido, las decisiones respecto a la acción del gobierno frente a la pandemia se dieron en tres periodos. El primer momento o primera fase, fue la concerniente a una identificación, seguimiento y contención de casos, asociado a una condición técnica de la pandemia. La segunda fase mantuvo la misma visión, con un crecimiento de los casos se pasó al proceso de transmisión comunitaria, con 
ello inició la jornada de sana distancia, apuntando hacia la mitigación. El programa de sana distancia pretendió limitar los contagios por medio de una perspectiva social, comunitaria no individualizada, con ello el gobierno a nivel nacional indicó la necesidad de cerrar todos los comercios, empresas, el ámbito educativo, ocio y otras actividades no esenciales. Así las acciones se centraron en los elementos de oferta de ocio, entretenimiento y empleo de los ciudadanos, limitando con ello la movilidad y tránsito de la población (Cejudo, et., al., 2020; Zazueta, y Jaramillo 2020; Macal, 2020) (Gráfico 1).

A la par se definieron dos programas, el primero respecto a la reorganización y ampliación hospitalaria, el segundo al seguimiento y detección de los contagios por medio del modelo Centinela (centrado en la detección de casos bajo una muestra estadística), aunado a la promoción de las mediadas de sana distancia, estornudo de etiqueta y lavado de manos. Esta reorganización y programas de mitigación permitieron a la Secretaría de Salud evitar la saturación de los hospitales, mas no disminuir el número de fallecimientos. En la tercera fase, se identificaron al menos dos perspectivas, la político-económica y la técnica, esta última liderada por los miembros del equipo de salubridad. Esta fase, enmarcada por el crecimiento de los contagios y el incremento de los fallecimientos, fue llamada la fase de nueva normalidad, la cual comenzó con decisiones regionalizadas (Cejudo, et., al., 2020; Zazueta, y Jaramillo 2020; Macal, 2020).

\section{Gráfico 1}

Evolución de personas infectadas por covid 19 en México (por semanas)

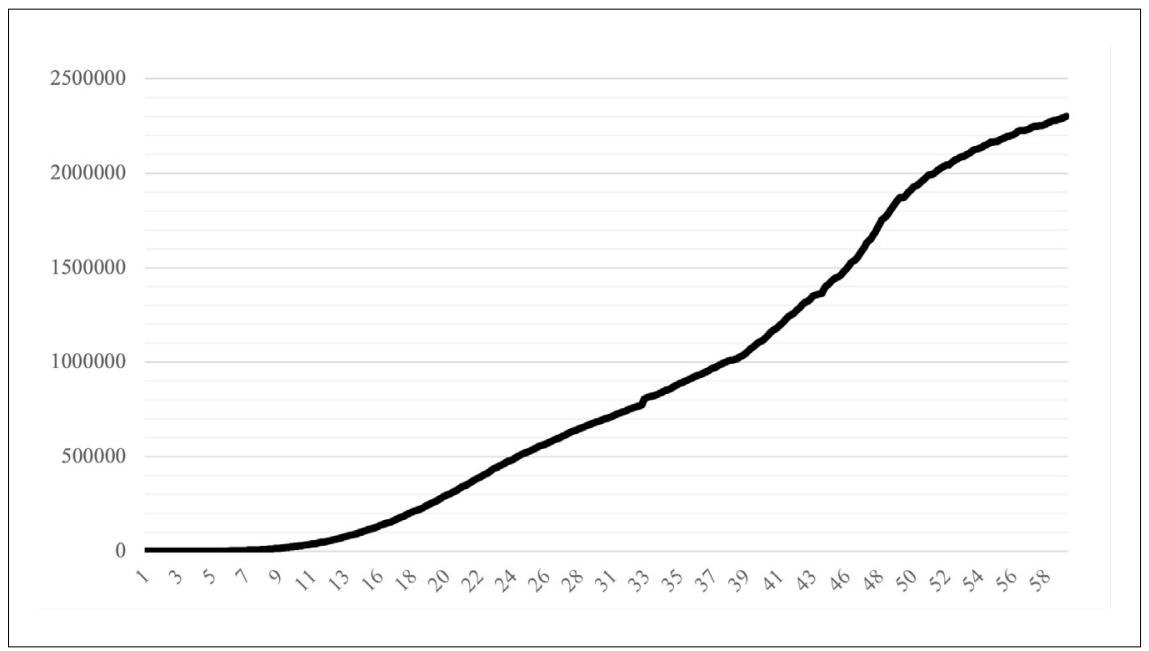

Fuente: Elaboración propia con datos de la Secretaría de Salud del Gobierno de México https://coronavirus.gob.mx/

$\star$ Fecha de corte al 15 de abril de 2021 
La lucha contra la pandemia tuvo como política principal del gobierno federal la de quedarse en casa, además de la promoción de sana distancia, que posteriormente se avanzó a la nueva normalidad a mediados de julio. A nivel nacional no se efectuaron medidas restrictivas ni sanciones hacia los individuos, pero se incitó a la sociedad a quedarse en casa durante el periodo que inició a mediados de marzo y que aún continúa. No hubo en ningún momento restricción federal ni aumento de facultades para el Poder Ejecutivo, debido a que no se declaró emergencia nacional, por ello las facultades del presidente no se modificaron durante el proceso, desde el inicio de la pandemia hasta ahora. Llevando desde marzo un seguimiento de la pandemia por parte del Consejo de Salubridad llamando a emergencia sanitaria y la toma de decisiones colegiada (Cejudo, et., al., 2020; Zazueta, y Jaramillo 2020; Macal, 2020).

En términos generales la percepción ciudadana favoreció el desempeño del presidente con una alta aprobación por encima del 60\% desde el inicio de su gestión, no es así respecto al desempeño en general del gobierno, principalmente en áreas como la Seguridad y la Economía con niveles de desaprobación por encima del 50-60\%. En términos de sanidad respecto a la pandemia, hubo visiones encontradas, parte de la población asumió posturas positivas respecto al desempeño del gobierno y la otra parte una visión negativa. La aprobación de la ciudadanía respecto al manejo de la emergencia sanitaria que ha hecho el presidente y su gobierno aumentó favorablemente al 45\%, la aprobación general del presidente López Obrador registró $58 \%{ }^{11}$, lo cual evidencia el amplio apoyo popular hacia el mandatario más que hacia su equipo de trabajo. Cabe destacar que los movimientos sociales, desde la llegada del gobierno de MORENA y López Obrador, han evidenciado una baja en intensidad y movilización. Sin embargo, en el año de inicio de la pandemia en el país destacan tres movilizaciones de grupos sociales: las movilizaciones feministas, que fue un fenómeno global más que nacional, movilizaciones en contra de la violencia, y movilizaciones sectorizadas opositoras al gobierno, estas últimas sucedieron principalmente a nivel local.

En términos económicos hubo al menos cinco medidas, aunque difusas por su deficiente implementación y paradójicamente errores en los procesos de comunicación. La primera fue el apoyo a adultos mayores y jóvenes, además de otros programas de creación de infraestructuras carreteras comunitarias y agrícolas. Basados en la política social, los programas de bienestar desplegaron sus apoyos económicos a sectores menos favorecidos otorgando adelantos de estos. La segunda medida fue la creación de créditos para micro y medianas empresas que habían respetado los derechos laborales durante el inicio de la pandemia, además de créditos para la vivienda. La tercera fue el adelanto de la dispersión de fondos destinados a los estados, con lo que se aseguraba el gasto anual de la federación en este rubro. La cuarta fue implementada por la Secretaría de Hacienda, al bajar las tasas de interés y

11 Según datos de la última encuesta publicada en un diario de circulación nacional (El Financiero). https://www.elfinanciero.com.mx/nacional/repunta-2-puntos-la-aprobacion-de-amlo 
agilizar el cobro de impuestos a grandes empresas deudoras, lo cual permitió mayor gasto en salud. Finalmente, la quinta fue la entrada en vigor del Tratado de Libre Comercio de América del Norte (T-MEC), fundamentalmente se establecieron dinámicas de apoyo comercial y sanitario con Estados Unidos, pese a los momentos de alta tensión en temas migratorios con el vecino del norte. Con todo lo anterior, el gobierno asumió que el Estado mexicano ya había comenzado los apoyos sociales (que otros países comenzaban a implementar) antes de la pandemia, por lo que no aumentó su gasto social, precisamente porque ya había iniciado antes de la emergencia sanitaria (Cejudo, et., al., 2020; Zazueta, y Jaramillo 2020; Macal, 2020).

Los cuestionamientos a las intervenciones económicas del gobierno durante este proceso han provenido de miembros de la sociedad civil, medios de comunicación tradicionales (televisión y diarios), intelectuales y grupos de empresarios, más que de la sociedad en general. El principal argumento en contra de las decisiones en temas económicos fue que el gobierno no se ha endeudado para implementar acciones contracíclicas además de que no condonó impuestos a empresas y no otorgó apoyos a estas (pese a los créditos a pequeñas y medianas empresas). Además de cuestionar la viabilidad de tres grandes proyectos del gobierno que no han sido detenidos durante la pandemia pese a su alto costo: el aeropuerto de Santa Lucía, el Tren Maya y la nueva refinería de Dos Bocas Tabasco (Cejudo, et., al., 2020; Zazueta, y Jaramillo 2020; Macal, 2020).

Otra de las críticas al gobierno han sido las acciones contrarias a los procesos de modernización medioambiental. El gasto progresivo para la recuperación de la empresa estatal Petróleos Mexicanos (PEMEX), el desarrollo de una nueva refinería y rehabilitación de otras parece desvanecer la idea de modernización medioambiental en el país. Sin embargo, esta idea se contrarresta con las políticas económicas y comerciales del nuevo tratado de libre Comercio con Estados Unidos y Canadá (T-MEC), debido a que el tratado comercial promueve el uso de energías limpias y demás actividades de modernización tecnológica para el desarrollo sustentable, además de la reciente firma del convenio de colaboración del gobierno mexicano para el desarrollo sustentable con la ONU. El segundo punto es precisamente la implementación de un programa social que pretende sembrar millones de árboles maderables distribuidos en miles de hectáreas al sur del país. Concurrentemente al programa de apoyo agrícola a campesinos de la misma región (Cejudo, et., al., 2020; Zazueta, y Jaramillo 2020; Macal, 2020).

\subsection{La pandemia en los estados: entre la resistencia y las limitaciones estructurales}

En términos generales, el gobierno federal no imprimió medidas coercitivas ni sanciones administrativas en contra de los ciudadanos, argumentando la defensa de los derechos humanos y por las condiciones estructurales de la sociedad mexicana asociadas a la informalidad, pobreza y desigualdad. En este sentido, cabe destacar 
un elemento discursivo del gobierno que es la constante crítica al neoliberalismo y la corrupción. El gobierno ha asociado a la política económica neoliberal con los grandes problemas del país con la corrupción, la desigualdad y la pobreza. De hecho, el presidente en sus conferencias matutinas, desde su llegada al poder, ha dedicado gran parte de estas a la crítica del modelo neoliberal y su crisis evidenciada aun con mayor fuerza durante la pandemia. Esta crítica se ha desarrollado en todas las áreas de la vida política y social del país por parte del presidente y el gobierno federal, comenzando por la desigualdad, la pobreza, y en efecto con la salud, esta última se ha asociado a las malas prácticas de los gobiernos predecesores con la deficiencia del servicio antes de la emergencia sanitaria, justificando las fallas durante la pandemia. Lo anterior es relevante debido a la estructura de las entidades y las condiciones económicas, sociales, sanitarias y técnicas con las que enfrentaría la tercera fase de la pandemia (Cejudo, et., al., 2020; Zazueta, y Jaramillo 2020; Macal, 2020).

En este proceso de nueva normalidad, la tercera fase de la pandemia consistió en la definición de las autoridades locales frente a la emergencia sanitaria. La cual fue abordada de forma heterogénea por las entidades federativas. Debido a la organización federal del país, son también facultades de los gobiernos estatales actuar como autoridades sanitarias. En este sentido, en algunos estados importantes por su capacidad económica y densidad de población, como Jalisco, se suscitaron actos violentos y coerción policial a miembros de la sociedad civil por no respetar la cuarentena y el uso de cubrebocas, algo similar en un par de municipios del norte del país, en donde se implementaron sanciones administrativas para la restricción de movilidad durante el periodo de sana distancia, en la fase dos de contagios en el país. Los lineamientos nacionales promovieron la libertad de los ciudadanos de decidir quedarse en casa, lo que a nivel estatal (en casos muy específicos como los ya mencionados) fue más restrictivo, pese a ello, respetando los lineamientos federales como marco general de actuación (Cejudo, et., al., 2020; Zazueta, y Jaramillo 2020; Macal, 2020).

\subsubsection{La estructura sanitaria}

En el punto focal de la tercera fase de la acción del gobierno, los estados comenzaron a hacerse cargo de la pandemia en sus territorios, claramente limitados por los lineamientos federales y del semáforo epidemiológico (Gobierno de México, $2020)^{12}$. En este proceso, se proyectaron medidas para la apertura paulatina en los sectores relevantes de la economía sobre la base de los indicadores establecidos a nivel nacional. Dichas medidas provocaron que algunos gobiernos locales municipales y estatales comenzaran a señalar sus diferencias con el gobierno federal, creando divisiones y resistencias de los gobiernos subestatales, principalmente por parte de gobiernos de oposición (Cejudo, et., al., 2020; Zazueta, y Jaramillo 2020; Macal, 2020).

12 https://coronavirus.gob.mx/ * 
Lo anterior permitió el desarrollo de acciones diferenciadas por cada uno de los gobiernos estatales, a su vez dejó ver las condiciones estructurales con las que enfrentarían la crisis sanitaria, por lo que la capacidad de respuesta ha sido resultado de estas diferencias (Cejudo, et., al., 2020; Zazueta, y Jaramillo 2020; Macal, 2020). Para contrastar los anterior, y según las dimensiones indicadas en el apartado metodológico, se señalan cuatro ideas observadas en la realidad estatal. El primer elemento refiere a la estructura sanitaria, la cual considera la situación previa a la pandemia y se observa a partir de cuatro indicadores: a) Población sin carencia por acceso a los servicios de salud; b) Tasa de consultorios; c) Tasa de médicos; d) Población que tardaría menos de dos horas en llegar a un hospital; e) Población derechohabiente que recibió servicios preventivos; f) Tasa de camas censables. En este sentido, se pueden puntualizar seis elementos, uno general y cinco específicos. El primer elemento, general, asume que las entidades con una estructura de salud más desarrollada y/o consolidada fueron aquellas en donde la letalidad fue inferior. Para clarificar lo anterior, en los gráficos 2-7, se puede apreciar que los estados con una menor tasa de médicos, menor tasa de consultorios, menor cantidad de camas de hospital, con una estructura poco consolidada de servicios preventivos y una menor cobertura de servicios de salud fueron aquellos que tuvieron una mayor tasa de letalidad, por lo que la estructura sanitaria previa a la pandemia manifestó mayores efectos en estados con una deficiente prestación de servicios e infraestructura sanitaria para atender la crisis (Macal, 2020; Lazreg, Angel y Saint-Martin, 2020).

\subsubsection{La actividad económica}

El segundo elemento refiere a la actividad económica, la cual contempla dos variables (Benton, Rissler y Wagner, 2020). Por un lado, observa el desempeño económico previo a la pandemia. El segundo elemento es la pobreza y pobreza extrema, identificando las condiciones sociales previas a la pandemia en cada entidad federativa (Galletta y Giommoni, 2020; Zazueta y Jaramillo, 2020). En este sentido, los gráficos 8-10 evidencian la relación entre la estructura económica y los efectos de la pandemia. En ellos se puede apreciar que los estados con menor capacidad económica previa a la pandemia, manifestaron mayores niveles de letalidad. 
Gráfico $2-7$

Relación de la estructura del sistema de salud y la pandemia en diferentes entidades

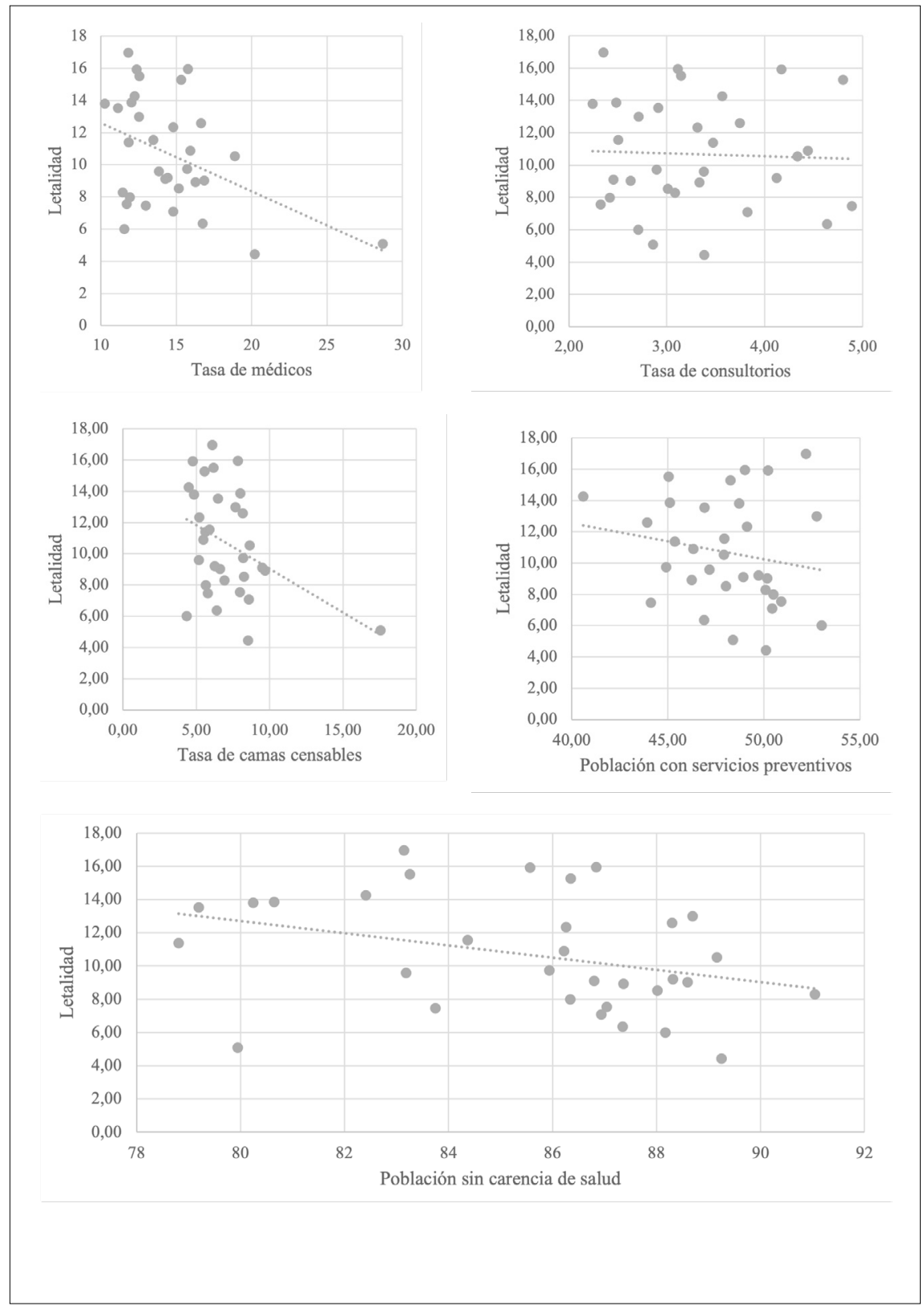

Fuente: elaboración propia 
Gráfico 8-10

Relación de la estructura del sistema de salud y la pandemia en contextos

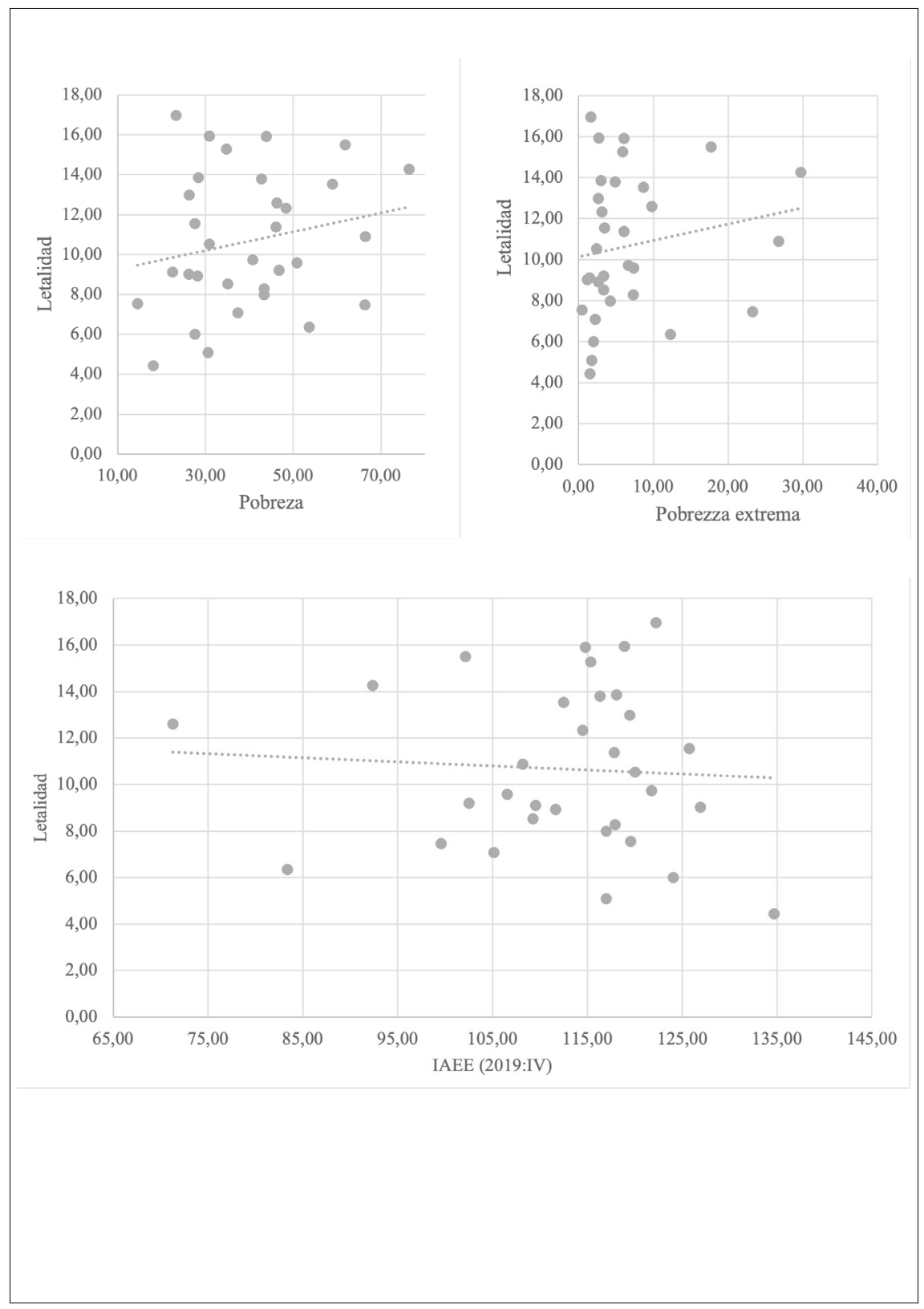

Fuente: elaboración propia 
Mapa 1

Relación entre letalidad, pobreza y actividad económica por estados

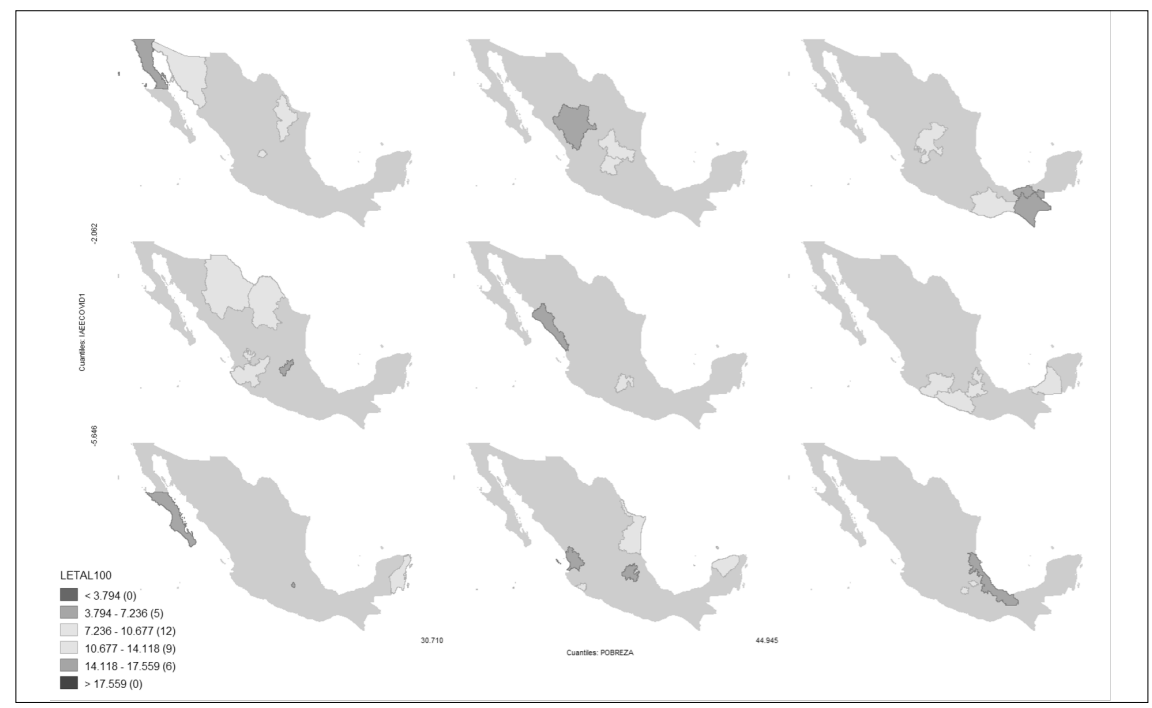

Fuente: elaboración propia

Mapas 2

Clasificación de estados según su estructura sanitaria, actividad económica, pobreza y letalidad causada por COVID 19 (Clúster jerárquico)

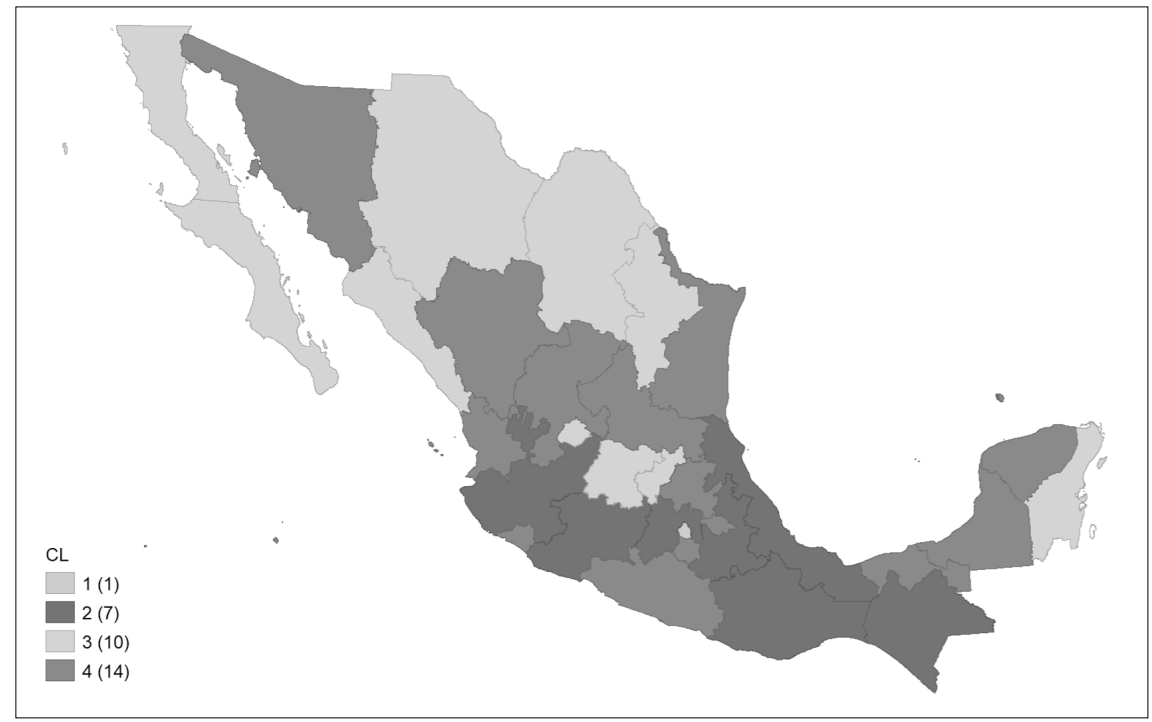

Fuente: elaboración propia 
Lo anterior considera que la estructura de las actividades económicas consolida un estado con mayor capacidad de respuesta frente a la crisis sanitaria, ya que se asume mayor capacidad de gasto para entenderla, y que concuerda con lo manifestado por la propia estructura sanitaria. Por otro lado, quizá uno de los elementos más relevantes es la relación de la pandemia con la estructura social. En este sentido, se puede concluir que aquellos estados con mayores niveles de pobreza (que no necesariamente son los estados con menor capacidad económica) fueron los que presentaron mayor tasa de letalidad provocada por la COVID 19.

\subsubsection{Las acciones de los gobiernos estatales}

El tercer elemento refiere a las acciones de política pública y el desempeño económico que es observado hasta el momento actual de la pandemia. En este sentido, se observa las políticas sociales y económicas desarrolladas por las entidades federativas para contrarrestar los efectos de la crisis sanitaria, la cual generó una latente crisis económica. Para ello se identifican las acciones concretas: a) programas y políticas de asistencia social; b) programas de digitalización administrativa; c) programas de estímulo económico; d) programas fiscales y sus efectos en la actividad económica (Cejudo, et., al., 2020). De acuerdo con este elemento, los estados que implementaron con más eficiencia sus políticas públicas encontraron mayores rendimientos económicos, ya que se han recuperado hasta el primer trimestre de 2021. Aunque estos estados fueron pocos, se encuentran los casos de Aguascalientes, Baja California, Oaxaca, Tabasco y Zacatecas. Lo anterior no implicó que la tasa de letalidad fuera menor dada las características estructurales de los estados, en donde es posible evidenciar que en aquellos en donde la pobreza era mayor, hubo mayor tasa de letalidad pese a su crecimiento o recuperación de la actividad económica. En este sentido, pocos estados (Aguascalientes y Baja California) lograron alcanzar esa recuperación controlando los niveles de prevención, infección y fallecimientos (Mapa 1). 
Tabla 1

Clasificación de estados por clúster según su estructura sanitaria, actividad económica, pobreza y letalidad causada por COVID 19 (Clúster jerárquico)

\begin{tabular}{ccccc}
\hline \multicolumn{5}{c}{ Clúster } \\
\hline 1 & 2 & 3 & & \\
& & Baja California & & \\
& Baja California & Sonora & \\
& Jalisco & Sur & Tamaulipas & Tlaxcala \\
Ciudad de & Estado de México & Chihuahua & Durango & Morelos \\
México & Puebla & Nuevo León & Zacatecas & Guerrero \\
& Oaxaca & Aguascalientes & Nayarit & Tabasco \\
& Chiapas & Guanajuato & Suis Po- & Campeche \\
& Veracruz & Querétaro & tosí & Yucatán \\
& & Quintana Roo & Hidalgo & \\
& & Sinaloa & & \\
& & &
\end{tabular}

$\star$ Tasa por población

$\star \star$ Medias por clúster (centers) / Number of clusters:

Ward's-linkage / Distance function: Euclidean

Fuente: elaboración propia

4 / Transformation: Standardize (Z) / Method:

Según lo expuesto, es posible evidenciar que las diferencias y similitudes entre entidades federativas mexicanas respecto a sus acciones frente a la crisis sanitaria tienen relación con las principales políticas públicas que fueron implementadas como respuesta emergente a este escenario crítico. Lo anterior se contrasta con las premisas esgrimidas por Klein (2007) a la luz de los objetivos de las acciones de gobierno frente a la crisis sanitaria. Como supuesto teórico, se evidencia que los gobiernos subestatales que desarrollaron acciones encaminadas a la contención de la enfermedad que permitiera mantener la economía a la par de la limitación de fallecimientos a causa de la COVID 19 fueron más exitosos en la medida que su estructura sanitaria, social y económica previa así lo permitiera como el caso de Aguascalientes, Guanajuato o Querétaro (clúster 3). En este sentido, las entidades que sufrieron mayores estragos sanitarios fueron aquellas cuya capacidad de respuesta y estructura sanitaria era limitada como lo evidenciado en el grupo de los estados como Guerrero o Tabasco (clúster 4) (Tabla 1).

Lo anterior evidencia que las acciones de gobierno para enfrentar la pandemia de las diversas entidades mexicanas tuvieron efectos diferenciados debido a su estructura económica, social y sanitarias previas, consolidando con ello una afectación mayor a entidades vulnerables con niveles altos de pobreza (Capano, et. al., 2020; Woo, 2020; Capano, 2020; Galletta y Giommoni, 2020; Zazueta y Jaramillo, 2020) (Mapa 1). Por ello se pueden establecer cuatro grupos de estados que en términos comparativos pueden agruparse en función de su capacidad de respuesta, estructura de salud, recuperación económica y estructura social. En términos generales, los estados 
del país que mejor desempeño manifestaron ante la crisis sanitaria tienen relación con lo anteriormente expresado, es decir, fueron aquellos que tenían, en términos comparativos, las condiciones estructurales necesarias para afrontar la pandemia (clúster 1 y 3: Mapa 2 y Tabla 1). En ellos se pueden apreciar principalmente las diferencias y similitudes entre los estados del sur (clúster 2 y 4: Mapa 2 y Tabla 1) y los estados del centro norte del país (clúster 1 y 3: Mapa 2 y Tabla 1).

\section{Conclusiones}

En una época en la que el exceso de información y noticias falsas pueden generar un pánico social y una suspicacia que hace creer en múltiples teorías, es evidente con los datos y la contrastación empírica mostrada constantemente que no era un virus que fuera posible menospreciar, las miles de víctimas registradas en varias entidades de manera tan rápida, brindaban sustento de que se requerían cambios en las políticas para solucionarlo de manera expedita y evitar su expansión, aunque las especificidades sobre el virus permanecen hasta ahora en la incertidumbre o ambigüedad, al igual que la vacuna pese a haber sido generada por varios laboratorios en tiempo récord para combatirle, ha sido un proceso continuo en el que las víctimas mortales continúan a nivel mundial, al igual que el número de contagios y la necesidad de una solución rápida (Devine, Gaskell, Jennings y Stoker, 2020).

A pesar de que no se estimulen los postulados del neoliberalismo de manera directa como sugería Klein (2007) mediante un capitalismo de desastre, han sido pocos los países que han ostentado los recursos suficientes para invertir en laboratorios que sean capaces de generar el número suficiente de vacunas, que, aunque sean comercializadas a un valor bajo, implican un alto costo político para quienes la administren. Este tipo de catástrofes a escala mundial representan oportunidades para quienes están a cargo de la política en un nivel que no se había visto en las últimas décadas, al menos en democracia. Sin embargo con el uso de herramientas que antes no se tenían, es posible que con esta crisis se hayan logrado más cambios en decisiones políticas, que los que se hubieran alcanzado mediante el acuerdo entre grupos o fracciones de partidos.

El control político derivado del reforzamiento de la opinión pública, además de construir una base sólida por métodos mediáticos, como el lanzamiento de mensajes en diversas plataformas y una presencia continuada, se ha visto afectado en distintas medidas para las diferentes latitudes de México, como se ha analizado en la distribución territorial plasmada en la representación espacial, por otros factores como el nivel de aceptación y popularidad de quien encabeza el Poder Ejecutivo a nivel nacional, o la conformación de las fuerzas políticas en las entidades en términos legislativos con una presencia importante del mismo partido en el poder, lo cual no se vincula la estructura económica dominante, pero sí la estructura de partido (o alianza oficialista) dominante en la conformación política actual mexicana. 
Por lo anterior es posible concluir que, si bien el caso de la aplicación del shock prolongado en este contexto no se equipara a un capitalismo de desastre, sí podría encuadrar por sus elementos de refuerzo de la clase en el poder, como una dominación política del desastre, a pesar de ser una clase política que en el discurso se distancia de los ideales neoliberales.

Estas diferencias en la distribución de una cantidad de elementos de conformación política, junto con la combinación de otras variables relacionadas a las capacidades económicas y sanitarias de las entidades han arrojado los cuatro subgrupos de estados según su estructura en salud, actividad económica, pobreza y letalidad que se refleja territorialmente con las diferentes combinaciones y usos políticos en el contexto de un prolongado shock provocado por la COVID-19 y una serie de medidas y cambios políticos diferenciados que han sido ineficientes hasta el momento para disminuir la problemática en cuanto a reducción de víctimas letales por el virus y la recuperación económica en México. 


\section{Referencias}

Animal Político (2020). "COVID-19 y crisis vinieron 'como anillo al dedo': AMLO” en animalpolítico.com. Recuperado el 8 de mayo de 2021: https://www.animalpolitico. com/2020/04/crisis-economica-salud-transitoria-saldremos-ponto-amlo/

Benton, J. E.; Rissler, G.; Wagner, S. (2020) "City and County Governments in the Time of COVID-19 and the Recession: The Long, and Winding Road", State and Local Government Review, 52(1):28-52.

Blau, A. (2020) "Defending Instrumental Rationality against Critical Theorists", Political Research Quarterly, 1-14

Capano, G. (2020) "Policy design and state capacity in the COVID-19 emergency in Italy: if you are not prepared for the (un)expected, you can be only what you already are", Policy and Society, (39):3, 326-344. DOI: 10.1080/14494035.2020.1783790

Capano, G.; Howlett, M.; Jarvis, D. S.L.; Ramesh, M. y Goyal, N. (2020) "Mobilizing Policy (In)Capacity to Fight COVID-19: Understanding Variations in State Responses", Policy and Society, (39)3: 285-308.

DOI: $10.1080 / 14494035.2020 .1787628$

Cejudo, G.M., Gómez, D., Michel, C.L., Lugo, D., Trujillo, H., Pimienta, C., Trujillo, H., Campos, J. (2020). “Federalismo en COVID: ¿Cómo responden los gobiernos estatales a la pandemia?" 8 de octubre, 2020. Laboratorio Nacional de Políticas Públicas: México. Disponible en: https://lnppmicrositio.shinyapps.io/FederalismoEnCovid/ / Federalismo en COVID: Plataforma interactiva sobre políticas estatales ante la pandemia por COVID-19 https://www.cide.edu/coronavirus/federalismo-covid/ / https:// Inppmicrositio.shinyapps.io/PoliticasEconomicasCovid19/

Consejo Nacional de Evaluación de la Política de Desarrollo Social CONEVAL: https:// www.coneval.org.mx/Medicion/MP/Paginas/Pobreza-2018.aspx

Devine, D.; Gaskell, J.; Jennings, W. y Stoker, G. (2020) “Trust and the Coronavirus Pandemic: What are the Consequences of and for Trust? An Early Review of the Literature", Political Studies Review, 1-12

El Financiero. https://www.elfinanciero.com.mx/nacional/repunta-2-puntos-laaprobacion-de-amlo

Fowler, L.; Kettler, J. J. y Witt, S. L. (2021) "Pandemics and Partisanship: Following Old Paths into Uncharted Territory", American Politics Research, 49(1):3-16.

Galletta, S. y Giommoni, T. (2020) "Pandemics and inequality", VOX, CEPR Policy Portal, (03 October) Recuperado de: https://voxeu.org/article/pandemics-and-inequality?utm_ source $=$ dlvr.it\&utm_medium $=$ linkedin 
Gobierno de México (2020). "NUEVA NORMALIDAD” en COVID-19 Medidas Económicas. Recuperado el 6 de mayo de 2021 en: https://www.gob.mx/ covid19medidaseconomicas/acciones-y-programas/nueva-normalidad-244196

Indicador Trimestral de la Actividad Económica Estatal del Instituto Nacional de Estadística y Geografia (INEGI):

https://www.inegi.org.mx/app/saladeprensa/noticia.html?id=6475

Instituto Nacional Electoral (INE).https://centralelectoral.ine.mx/2018/08/23/concluyeine-la-integracion-del-congreso-de-la-union/

Kincaid, J. y Leckrone, J.W. (2020) "Partisan Fractures in U.S. Federalism's COVID-19 Policy Responses", State and Local Government Review, 52(4):298-308

Klein, N. (2007). La Doctrina del Shock. El auge del capitalismo del desastre. Paidós: España. ISBN: 978-607-9377-55-7.

Korstanje, M. E. (2012). "Naomí Klein. La Doctrina del Shock: el Auge del Capitalismo" en Empiria. Revista de metodología de ciencias sociales 0(24):209. doi: 10.5944/ empiria.24.2012.850.

Lange, C. (2010). "La Doctrina del Shock. El auge del capitalismo del desastre". Revista INVI 25(70):225-27. doi: 10.4067/s0718-83582010000300007.

Lazreg, N.; Angel, A.; y Saint-Martin, D. (2020) “Are They All the Same? The Distribution of Personal Wealth Between the Left and the Right in Latin America", Journal of Politics in Latin America, 1-19. DOI: 10. 1177/ 1866 802X 20975036

Macal, D. (2020). "Factores de la demanda médica no atendida en los servicios públicos del Sistema de Salud mexicano. Modelo factorial exploratorio". Revista de Administración Pública, (LV)2: 65-90.

McDonald III, B. D.; Goodman, C. B. y Hatch, M. E. (2020) "Tensions in State-Local Intergovernmental Response to Emergencies:The Case of COVID-19", State and Local Government Review, 52(3):186-194

Martínez-Hernández, A. (2019). "El poder presidencial en México en la Constitución de 1917: la relación Ejecutivo-Legislativo después de la transición política". Caleidoscopio - Revista Semestral de Ciencias Sociales y Humanidades, 22(39):13-50 DOI: https://doi. org/10.33064/39scrscsh2002

(2020) "Las elecciones del fin de ciclo: el giro a la izquierda en México 2018 y el cambio en el sistema de partidos”. En Alcántara, Manuel (Dir.) 2020. América Latina vota (2017-2019). Tecnos, Madrid, España, (Cap. X: 357-390) 
Rocco, P.; Béland, D. y Waddan, A. (2020) "Stuck in neutral? Federalism, policy instruments, and counter-cyclical responses to COVID-19 in the United States", Policy and Society, (39):3: 458-477, DOI: 10.1080/14494035.2020.1783793

Sánchez Arenas, R. (2020) "Intervenciones no farmacológicas y conductas preventivas para prevenir la propagación de COVID-19". Revista de Administración Pública, (LV)2: 23-38

Secretaría de Salud del Gobierno de México: Plataforma https://coronavirus.gob.mx/ / https://datos.covid-19.conacyt.mx/\#DOView / Dirección General de Epidemiología: Sistema de Información de la Red IRAG. Secretaría de Salud: https://www.gits. igg.unam.mx/red-irag-dashboard/reviewHome / http://www.dgis.salud.gob.mx/ contenidos/basesdedatos/da_recursos_gobmx.html

Shringare, A. y Fernandes, S. (2020). "COVID-19 Pandemic in India Points to Need for a Decentralized Response”. State and Local Government Review, 52(3): 195-199

Simon, H. (1957). “A Behavioral Model of Rational Choice”, en Models of Man, Social and Rational: Mathematical Essays on Rational Human Behavior in a Social Setting. New York:Wiley.

. (1989) Naturaleza y límites de la razón humana. Fondo de Cultura Económica. México.

Sistema de Información de Derechos Sociales del Consejo Nacional de Evaluación de la Política de Desarrollo Social (CONEVAL): Módulo de Condiciones Socioeconómicas MCS-ENIGH 2010 y el Modelo Estadístico 2018 para la continuidad del MCSENIGH. / Sectorial (SINAIS) 2012-2017, Recursos en Salud, Cubos dinámicos de la SSA-DGIS, 2012 y 2017 / MCS-ENIGH 2008, 2010, 2012, 2014 y el MEC del MCSENIGH 2016 y 2018. https://www.coneval.org.mx/Medicion/Paginas/Sistema-deinformacion-de-derechos-sociales.aspx /

Taggart, P. y Pirro, A. (2021). "European populism before the pandemic: ideology, Euroscepticism, electoral performance, and government participation of 63 parties in 30 countries", Italian Political Science Review, 1-24. doi:10.1017/ipo.2021.13

Woo, J. J. (2020). "Policy capacity and Singapore's response to the COVID-19 pandemic", Policy and Society, (39):3, 345-362, DOI: 10.1080/14494035.2020.1783789

Zazueta Borboa, J. y Jaramillo Molina, M. (2020). "El impacto desigual de la pandemia: Determinantes socioeconómicas y de salud en las tasas de fatalidad del Covid19 en México". Revista de Administración Pública, (LV)2: 91-108.

Enviado: 21 de mayo de 2021

Aceptado: 09 de julio de 2021 


\section{ANEXO}

Tabla 2b: Clasificación de estados por clúster según su estructura sanitaria, actividad económica, pobreza y letalidad causada por COVID 19 (Clúster jerárquico)

\begin{tabular}{lcccc}
\hline \multirow{2}{*}{ Variable } & \multicolumn{4}{c}{ Clúster } \\
\cline { 2 - 5 } & 1 & 2 & 3 & 4 \\
\hline Letalidad por COVID 19 & 5.082 & 12.830 & 10.154 & 10.373 \\
\hline Cobertura de salud & 79.942 & 81.186 & 86.923 & 87.144 \\
\hline Consultorios & 2.861 & 3.244 & 2.660 & 3.792 \\
\hline Médicos & 28.700 & 11.860 & 14.007 & 15.169 \\
\hline Distancia de hospitales & 96.077 & 88.327 & 96.439 & 93.409 \\
\hline Servicios preventivos & 48.380 & 45.110 & 50.537 & 47.795 \\
\hline Camas censables & 17.542 & 5.914 & 7.009 & 6.949 \\
\hline Pobreza & 30.550 & 54.378 & 26.021 & 43.329 \\
\hline $\begin{array}{l}\text { Índice de actividad económica estatal } \\
\text { (IAEE:2021) }\end{array}$ & -10.506 & -2.921 & -5.677 & -4.158 \\
\hline
\end{tabular}

$\star$ Tasa por población

$\star \star$ Medias por clúster (centers) / Number of clusters: 4 / Transformation: Standardize (Z) / Method: Ward's-linkage / Distance function: Euclidean

Fuente: elaboración propia

Tabla 3a: La pandemia en los estados (infectados confirmados, defunciones, letalidad)

\begin{tabular}{lcccc}
\hline Estado & Población & Confirmados & Defunciones & Letalidad \\
\hline Aguascalientes & $1,425,607$ & 25605 & 2309 & 9.02 \\
\hline Baja California & $3,769,020$ & 47153 & 7999 & 16.96 \\
\hline Baja California Sur & 798,447 & 29487 & 1307 & 4.43 \\
\hline Campeche & 928,363 & 9173 & 1155 & 12.59 \\
\hline Chiapas & $5,543,828$ & 10713 & 1528 & 14.26 \\
\hline Chihuahua & $3,741,869$ & 49602 & 6439 & 12.98 \\
\hline Ciudad de México & $9,209,944$ & 627325 & 31882 & 5.08 \\
\hline Coahuila & $3,146,771$ & 67481 & 6148 & 9.11 \\
\hline Colima & 731,391 & 11046 & 1163 & 10.53 \\
\hline Durango & $1,832,650$ & 32998 & 2337 & 7.08 \\
\hline Guanajuato & $6,166,934$ & 129562 & 10347 & 7.99 \\
\hline Guerrero & $3,540,685$ & 38776 & 4221 & 10.89 \\
\hline
\end{tabular}




\begin{tabular}{lllll}
\hline Hidalgo & \multicolumn{1}{c}{$3,082,841$} & \multicolumn{1}{c}{37585} & \multicolumn{1}{c}{5982} & \multicolumn{1}{c}{15.92} \\
\hline Jalisco & $8,348,151$ & 84179 & 11668 & 13.86 \\
\hline México & $16,992,418$ & 240197 & 33136 & 13.80 \\
\hline Michoacán & $4,748,846$ & 46315 & 5273 & 11.39 \\
\hline Morelos & $1,971,520$ & 31264 & 2997 & 9.59 \\
\hline Nayarit & $1,235,456$ & 11568 & 1767 & 15.27 \\
\hline Nuevo León & $5,784,442$ & 121343 & 9161 & 7.55 \\
\hline Oaxaca & $4,132,148$ & 45083 & 3366 & 7.47 \\
\hline Puebla & $6,583,278$ & 81425 & 11017 & 13.53 \\
\hline Querétaro & $2,368,467$ & 67117 & 4028 & 6.00 \\
\hline Quintana Roo & $1,857,985$ & 22093 & 2553 & 11.56 \\
\hline San Luis Potosí & $2,822,255$ & 61484 & 5096 & 8.29 \\
\hline Sinaloa & $3,026,943$ & 37156 & 5923 & 15.94 \\
\hline Sonora & $2,944,840$ & 72073 & 6433 & 8.93 \\
\hline Tabasco & $2,402,598$ & 62821 & 3993 & 6.36 \\
\hline Tamaulipas & $3,527,735$ & 55629 & 4742 & 8.52 \\
\hline Tlaxcala & $1,342,977$ & 19108 & 2356 & 12.33 \\
\hline Veracruz & $8,062,579$ & 58883 & 9133 & 15.51 \\
\hline Yucatán & $2,320,898$ & 36199 & 3521 & 9.73 \\
\hline Zacatecas & $1,622,138$ & 29491 & 2713 & 9.20 \\
\hline Nacional & $126,014,024$ & 2299934 & 211693 & 9.20 \\
\hline
\end{tabular}

Fuente: Elaboración propia con datos de la Secretaría de Salud del Gobierno de México. Fecha de corte al 15 de abril de 2021

Tabla 3b: Evolución de la actividad económica estatal (2019-2020, por trimestre)

\begin{tabular}{|c|c|c|c|c|c|c|}
\hline \multirow{4}{*}{ Estado } & \multicolumn{3}{|c|}{2019} & \multicolumn{3}{|c|}{2020} \\
\hline & \multicolumn{6}{|c|}{ IV TRIMESTRE } \\
\hline & \multirow{2}{*}{$\begin{array}{l}\text { Índice } \\
\text { (base } \\
\text { 2013) }\end{array}$} & \multicolumn{2}{|c|}{ Variación porcentual } & \multirow{2}{*}{$\begin{array}{l}\text { Índice } \\
\text { (base } \\
2013 \text { ) }\end{array}$} & \multicolumn{2}{|c|}{ Variación porcentual } \\
\hline & & Trimestral & Anual & & Trimestral & Anual \\
\hline Aguascalientes & 126.9 & (-) 1.8 & $(-) 2.6$ & 127.5 & 2.5 & 0.5 \\
\hline Baja California & 122.2 & (-) 2.0 & 0.3 & 126.7 & 2.9 & 3.7 \\
\hline Baja California Sur & 134.7 & (-) 2.7 & $(-) 6.2$ & 114.0 & 9.0 & (-) 15.4 \\
\hline Campeche $^{\text {a }}$ & 71.3 & (-) 1.2 & (-) 1.4 & 66.0 & 2.0 & $(-) 7.4$ \\
\hline Coahuila & 109.5 & (-) 4.4 & (-) 2.4 & 106.9 & 4.2 & $(-) 2.4$ \\
\hline Colima & 120.0 & (-) 1.3 & 5.3 & 111.6 & 3.0 & $(-) 7.1$ \\
\hline
\end{tabular}




\begin{tabular}{|c|c|c|c|c|c|c|}
\hline \multirow{4}{*}{ Estado } & \multicolumn{3}{|c|}{2019} & \multicolumn{3}{|c|}{2020} \\
\hline & \multicolumn{6}{|c|}{ IV TRIMESTRE } \\
\hline & \multirow{2}{*}{$\begin{array}{l}\text { Índice } \\
\text { (base } \\
2013 \text { ) }\end{array}$} & \multicolumn{2}{|c|}{ Variación porcentual } & \multirow{2}{*}{$\begin{array}{l}\text { Índice } \\
\text { (base } \\
2013 \text { ) }\end{array}$} & \multicolumn{2}{|c|}{ Variación porcentual } \\
\hline & & Trimestral & Anual & & Trimestral & Anual \\
\hline Chiapas & 92.3 & (-) 1.1 & 0.3 & 91.1 & 0.7 & (-) 1.3 \\
\hline Chihuahua & 119.5 & $(-) 0.7$ & $(-) 1.5$ & 117.1 & 1.6 & $(-) 2.0$ \\
\hline Ciudad de México & 117.0 & $(-) 0.9$ & 0.1 & 106.5 & 1.7 & $(-) 9.0$ \\
\hline Durango & 105.2 & (-) 3.1 & (-) 2.6 & 104.3 & 3.1 & (-) 0.8 \\
\hline Guanajuato & 117.0 & $(-) 1.7$ & $(-) 2.3$ & 115.5 & 2.4 & $(-) 1.3$ \\
\hline Guerrero & 108.2 & $(-) 2.0$ & $(-) 2.0$ & 105.8 & 5.9 & $(-) 2.2$ \\
\hline Hidalgo & 114.8 & (-) 2.3 & $(-) 2.9$ & 107.5 & 4.0 & $(-) 6.4$ \\
\hline Jalisco & 118.1 & $(-) 1.2$ & $(-) 0.9$ & 115.0 & 3.4 & $(-) 2.6$ \\
\hline México & 116.3 & 0.6 & 0.7 & 112.5 & 4.4 & $(-) 3.3$ \\
\hline Michoacán & 117.8 & $(-) 0.4$ & 0.5 & 112.6 & 2.4 & $(-) 4.4$ \\
\hline Morelos & 106.5 & (-) 2.3 & (-) 5.1 & 99.0 & 2.2 & (-) 7.0 \\
\hline Nayarit & 115.3 & $(-) 0.4$ & $(-) 1.0$ & 108.7 & 4.2 & $(-) 5.8$ \\
\hline Nuevo León & 119.5 & $(-) 3.1$ & $(-) 2.3$ & 117.8 & 3.9 & $(-) 1.5$ \\
\hline Oaxaca & 99.6 & $(-) 4.2$ & $(-) 6.6$ & 104.1 & 4.9 & 4.5 \\
\hline Puebla & 112.5 & $(-) 3.4$ & $(-) 2.6$ & 107.1 & 0.9 & $(-) 4.8$ \\
\hline Querétaro & 124.1 & $(-) 2.1$ & $(-) 1.7$ & 120.9 & 4.7 & $(-) 2.6$ \\
\hline Quintana Roo & 125.7 & (-) 1.9 & (-) 2.1 & 100.2 & 9.7 & (-) 20.3 \\
\hline San Luis Potosí & 117.9 & $(-) 2.5$ & $(-) 1.3$ & 117.2 & 1.7 & $(-) 0.6$ \\
\hline Sinaloa & 118.9 & $(-) 1.2$ & 0.3 & 114.8 & 0.6 & $(-) 3.5$ \\
\hline Sonora & 111.7 & $(-) 3.8$ & $(-) 2.1$ & 110.5 & 2.6 & $(-) 1.0$ \\
\hline Tabasco & 83.4 & 1.1 & 4.4 & 85.0 & 2.7 & 1.9 \\
\hline Tamaulipas & 109.3 & $(-) 0.4$ & 1.8 & 102.3 & 2.0 & $(-) 6.4$ \\
\hline Tlaxcala & 114.5 & $(-) 7.8$ & $(-) 1.7$ & 106.2 & $(-) 0.2$ & $(-) 7.3$ \\
\hline Veracruz & 102.1 & $(-) 0.6$ & 1.0 & 95.7 & 3.3 & $(-) 6.3$ \\
\hline Yucatán & 121.8 & $(-) 0.9$ & $(-) 0.6$ & 115.8 & 3.2 & $(-) 4.9$ \\
\hline Zacatecas & 102.5 & (-) 1.5 & (-) 3.8 & 104.4 & 1.1 & 1.8 \\
\hline
\end{tabular}

Fuente: Indicador Trimestral de la Actividad Económica Estatal del Instituto Nacional de Estadística y Geografía (INEGI) https://www.inegi.org. $m x /$ app/saladeprensa/noticia.html?id=6475 
Tabla 3c: Planes y programas implementados por los estados durante la pandemia (2019-2020)

\begin{tabular}{|c|c|c|c|c|c|c|}
\hline Estado & $\begin{array}{l}\text { Programas } \\
\text { de Asistencia } \\
\text { Social }\end{array}$ & $\begin{array}{l}\text { Programas de } \\
\text { Digitalización }\end{array}$ & $\begin{array}{l}\text { Programas } \\
\text { de Estímulo } \\
\text { Económico }\end{array}$ & $\begin{array}{l}\text { Programas } \\
\text { Fiscales }\end{array}$ & $\begin{array}{c}\text { Total } \\
\text { programas }\end{array}$ & $\begin{array}{l}\text { Políticas } \\
\text { sociales }\end{array}$ \\
\hline Aguascalientes & 4 & & 10 & 16 & 30 & 30 \\
\hline Baja California & 8 & 2 & 8 & 2 & 20 & 19 \\
\hline $\begin{array}{l}\text { Baja California } \\
\text { Sur }\end{array}$ & 2 & & 6 & 5 & 13 & 6 \\
\hline Campeche & & & & & & 13 \\
\hline Chiapas & 1 & & 1 & & 2 & 10 \\
\hline Chihuahua & 6 & 1 & 8 & 4 & 19 & 37 \\
\hline $\begin{array}{l}\text { Ciudad de } \\
\text { México }\end{array}$ & 11 & & 10 & 1 & 22 & 35 \\
\hline Coahuila & 1 & 1 & 5 & 5 & 12 & 9 \\
\hline Colima & 3 & & 3 & 8 & 14 & 25 \\
\hline Durango & & 1 & 2 & & 3 & 18 \\
\hline Guanajuato & 7 & 2 & 8 & 4 & 21 & 38 \\
\hline Guerrero & 2 & & 2 & 5 & 9 & 15 \\
\hline Hidalgo & 10 & 2 & 6 & 1 & 19 & 29 \\
\hline Jalisco & 13 & 1 & 13 & & 27 & 22 \\
\hline México & 3 & & 6 & 7 & 16 & 15 \\
\hline Michoacán & 3 & 3 & 2 & 9 & 17 & 14 \\
\hline Morelos & 2 & & 6 & 1 & 9 & 21 \\
\hline Nayarit & & 1 & 6 & 4 & 11 & 9 \\
\hline Nuevo León & 2 & 2 & & & 4 & 19 \\
\hline Oaxaca & 5 & 2 & 12 & 4 & 23 & 10 \\
\hline Puebla & 9 & 1 & 9 & 2 & 21 & 11 \\
\hline Querétaro & 9 & & 5 & 3 & 17 & 20 \\
\hline Quintana Roo & 5 & 2 & 1 & 11 & 19 & 18 \\
\hline San Luis Potosí & 4 & & 14 & 8 & 26 & 23 \\
\hline Sinaloa & & 2 & 9 & 1 & 12 & 11 \\
\hline Sonora & 6 & 2 & 4 & 4 & 16 & 34 \\
\hline Tabasco & 2 & 1 & 1 & & 4 & 5 \\
\hline Tamaulipas & 2 & 1 & 3 & & 6 & 6 \\
\hline Tlaxcala & 3 & & 6 & 4 & 13 & 10 \\
\hline Veracruz & 7 & 2 & 1 & 1 & 11 & 13 \\
\hline Yucatán & 7 & & 19 & 9 & 35 & 34 \\
\hline
\end{tabular}




\begin{tabular}{lllllll}
\hline Estado & $\begin{array}{c}\text { Programas } \\
\text { de Asistencia } \\
\text { Social }\end{array}$ & $\begin{array}{c}\text { Programas de } \\
\text { Digitalización }\end{array}$ & $\begin{array}{c}\text { Programas } \\
\text { de Estímulo } \\
\text { Económico }\end{array}$ & $\begin{array}{c}\text { Programas } \\
\text { Fiscales }\end{array}$ & $\begin{array}{c}\text { Total } \\
\text { programas }\end{array}$ & $\begin{array}{c}\text { Políticas } \\
\text { sociales }\end{array}$ \\
\hline Zacatecas & 4 & 15 & 1 & 20 & 50 \\
\hline Nacional & 141 & 29 & 201 & 120 & 491 & 629 \\
\hline
\end{tabular}

Fuente: Elaboración propia con datos del Proyecto Federalismo en COVID: Plataforma interactiva sobre políticas estatales ante la pandemia por COVID-19: https://www.cide.edu/coronavirus/ federalismo-covid/; https://lnppmicrositio.shinyapps.io/PoliticasEconomicasCovid19/

Figura 1: Dendograma de estados según su estructura sanitaria, actividad económica, pobreza y letalidad causada por COVID 19 (Clúster jerárquico)



Fuente: elaboración propia 